\title{
Therapeutic Autologous Dendritic Cells
}

National Cancer Institute

\section{Source}

National Cancer Institute. Therapeutic Autologous Dendritic Cells. NCI Thesaurus. Code C2594.

A population of a type of antigen-presenting cell (APC), the dendritic cell (DC), harvested from a patient and grown in vitro in the presence of tumor-associated antigens (TAAs) derived from the patient's tumor (a technique known as 'pulsing') and then injected back into the patient; autologous DCs so manipulated may stimulate a specific cell-mediated antitumoral cytotoxicity. DCs derived from a patient may also be fused with the patient's tumor cells in vitro to combine sustained tumor antigen expression with the antigenpresenting and immunostimulatory capacities of DCs; when injected back into the patient, these autologous DC-tumor cell hybrids (fusion cells) may stimulate an active antitumoral immune response. 